\title{
Annual cycle of liveweight and reproductive changes of farmed male fallow deer (Dama dama) and the effect of daily oral administration of melatonin in summer on the attainment of seasonal fertility
}

\author{
G. W. Asher, A. M. Day and G. K. Barrell* \\ Ruakura Animal Research Station, Ministry of Agriculture \& Fisheries, Private Bag, Hamilton, \\ New Zealand and *Animal Sciences Group, Lincoln College, Canterbury, New Zealand
}

\begin{abstract}
Summary. Entire bucks $(\mathrm{N}=7)$ exhibited pronounced liveweight gains over spring and summer months (October-February), to reach a peak mean weight of $59.8 \mathrm{~kg}$, and rapid liveweight losses over the rutting period (April-May) with a minimum mean liveweight of $54 \cdot 2 \mathrm{~kg}$. Mean neck girth and serum testosterone levels increased during late summer (January-March) and peaked at $387 \mathrm{~mm}$ and $12 \mathrm{ng} / \mathrm{ml}$ respectively immediately before the onset of the rut (April). Thereafter both measures declined during winter and spring months (June-December). Bucks castrated prepubertally $(\mathrm{N}=11)$ exhibited similar but less pronounced changes in mean liveweight and neck girth, in the absence of any change in testosterone secretion. Peak mean testicular diameter of entire bucks $(39 \mathrm{~mm})$ occurred immediately before the rut and was followed by testicular regression over winter and spring months (June-November), such that the testes attained their minimum mean size of $18 \mathrm{~mm}$ diameter in early summer (November). Motile spermatozoa were absent from ejaculates collected in summer (November 1983, 1984; January 1984). However, ejaculates collected pre-rut (late March), immediately post-rut (June) and in early spring (September) contained successively increasing numbers of motile spermatozoa.

A further 14 polled, entire bucks were given orally $5 \mathrm{mg}(\mathrm{N}=7$; Group A) or $20 \mathrm{mg}$ $(\mathrm{N}=7$; Group B) melatonin at $15: 30 \mathrm{~h}$ daily from 1 December 1983 to 14 January 1984 (45 days). Seven control bucks (Group C) received vehicle ration only. The measurements taken for bucks in Groups A and B were not significantly different $(P>0 \cdot 1)$ on any sampling date and the data for these 2 groups were pooled. Mean serum testosterone concentrations and mean ejaculate volume were not significantly different between melatonin-treated and control bucks on any sampling date, although other measures exhibited significant differences $(P<0.05)$ at various treatment or post-treatment dates: melatonin-treated bucks showed a transiently greater increase in neck muscle development during and immediately after treatment, a slight retardation of liveweight gain between 45 and 75 days after treatment, an earlier peak in maximum mean testicular diameter and an earlier onset of sperm presence in ejaculates.
\end{abstract}

\section{Introduction}

Farming of fallow deer (Dama dama) for venison production is proving to be a highly profitable venture in New Zealand. Although the current high commercial value of breeding stock has increased the importance of obtaining optimal reproductive performance from these animals, little information is available on basic biological aspects of fallow deer reproduction. 
Previous studies on the reproductive seasonality of entire adult fallow bucks have investigated seasonal changes in testicular size and morphology (Chapman \& Chapman, 1970, 1975; Chaplin \& White, 1972; Baker, 1973), accessory glands (Chapman \& Chapman, 1979), antlers (Chapman \& Chapman, 1975) and the prepuce (Kennaugh et al., 1977), mainly in tissue samples from killed bucks. They have provided a general description of seasonal reproductive changes in fallow bucks, but have not provided information about the precise timing of reproductive events as can be gained from sequential studies on individual animals.

The importance of the seasonal variation of the daily light:dark ratio in mediating the timing of annual reproductive cycles of many non-equatorial mammalian species has long been recognized, either from the relationship observed between photoperiod and sexual activity or by the results of experimental photoperiodic manipulation (Thibault et al., 1966). The generally accepted hypothesis that the strict seasonality of reproduction in fallow deer is mediated by the prevalent photoperiodic regimen (Chaplin \& White, 1972; Chapman \& Chapman, 1975; Eaton, 1980) has been inferred largely from experiments on red deer (Jaczewski, 1954) and sika deer (Goss, 1983) in which artificial photoperiodic regimens altered the timing of the annual antler and testicular growth cycles of males.

In sheep the daily pattern of melatonin secretion from the pineal gland mediates the effects of photoperiod on reproduction (Rollag et al., 1978; Lincoln \& Almeida, 1981). A physiological 'short-day' state has been achieved by administering exogenous melatonin, orally (e.g. Kennaway et al., 1981; Symons et al., 1983) or by subcutaneous injections (e.g. Kennaway \& Seamark, 1980; Nett \& Niswender, 1982). In seasonally anoestrous ewes, such treatments have resulted in lowered blood prolactin concentrations (Kennaway et al., 1981) and the induction of oestrus and ovulation (Nett \& Niswender, 1982).

Daily administration of exogenous melatonin to seasonally anoestrous or prepubertal red deer hinds reduced serum prolactin concentrations and induced premature pelage changes (Webster \& Barrell, 1985), advanced the onset of oestrus and ovulation (Adam \& Atkinson, 1984; Webster \& Barrell, 1985) and advanced the calving season (Webster \& Barrell, 1985). Furthermore, daily oral administration of melatonin to white-tailed deer bucks (Bubenik, 1983) and red deer stags (Adam \& Atkinson, 1984) advanced the date of antler mineralization, and rutting behaviour in red deer stags.

In the present study groups of entire and prepubertally castrated bucks were monitored over a 13-month period to investigate seasonal changes in liveweight, neck girth and serum testosterone concentrations (entire and castrated bucks), as well as testicular size and sperm characteristics (entire bucks). In addition, a concurrent study investigated the effects of daily oral administration of exogenous melatonin during a 45-day period in summer on the attainment of reproductive function in entire fallow bucks. Antler data were not available because the entire bucks were polled to reduce problems which might have been caused by aggressive behaviour during repeated handling.

\section{Materials and Methods}

Animals and management. Polled entire bucks $(\mathrm{N}=21$, including 2 vasectomized animals) and 11 prepubertally castrated (at 5 months of age) bucks, all 22 months old at the start (October 1983) of the trial period (13 months) were grazed together except for a 54-day period from 22 November 1983 and 14 January 1984. During this period, the entire bucks were allocated to 3 groups ( $N=7$; Groups $A, B$ and $C)$ and separated from the castrated bucks. A potential requirement for additional sire bucks for other trials in 1984 necessitated placing several of the larger fertile bucks and 2 vasectomised bucks into Group C (controls) as there was no guarantee that their reproductive competence would not be compromised if they had been placed in melatonin treatment groups. As a result, the pretreatment (22 November) mean ( \pm s.d.) liveweight of the control bucks $(51 \cdot 2 \pm 2 \cdot 2 \mathrm{~kg}$ ) was slightly, but not significantly $(P>0 \cdot 1$; Student's $t$ test $)$, heavier than that of bucks in Group A $(49 \cdot 1 \pm 3 \cdot 1 \mathrm{~kg})$ and Group B $(49.7 \pm 1.6 \mathrm{~kg})$.

The deer were contained in high fenced paddocks ( 0.25 ha) on the Ruakura Animal Research Station $\left(37^{\circ} 46^{\prime} \mathrm{S}\right.$, $175^{\circ} 20^{\prime} \mathrm{E}$ ) and grazed on ryegrass-white clover pastures. Pasture on offer was maintained at reasonable levels 
throughout the monitoring period and there was no necessity to resort to feeding of concentrate rations other than as a vehicle for melatonin administration.

Blood sampling, weighing and neck girth measurements. The bucks were mustered into a covered handling shed, individually restrained in a cradle device and blood sampled $(\sim 10 \mathrm{ml})$ into serum Vacutainers by jugular venepuncture at fortnightly intervals from October 1983 until June 1984 (the period spanning the rut) and thereafter at monthly intervals. Liveweights were recorded using an electronic load cell (Tru-Test NZ Ltd, Auckland, NZ) supporting the cradle. The sensitivity and resolution of the weighing apparatus was $0.2 \mathrm{~kg}$ and the accuracy was within $2 \%$ when checked frequently with 25,50 , and $75 \mathrm{~kg}$ weights. Neck girths, immediately cranial to the larynx, were measured using a plastic measuring tape.

Blood samples were chilled to $\sim 5^{\circ} \mathrm{C}$ and then centrifuged at $1000 \mathrm{~g}$ for $30 \mathrm{~min}$. The serum was transferred to glass vials and stored at $-10^{\circ} \mathrm{C}$ until assayed.

Testicular measurements and semen collection. At approximately 2-month intervals, the 19 fertile bucks were heavily sedated with an i.m. injection of an aqueous mixture of $5 \mathrm{mg}$ ketamine hydrochloride (Ketalar; Parke Davis Pty Ltd, U.S.A.) and $5 \mathrm{mg}$ xylazine hydrochloride (Rompun; Bayer Leverkusen, Germany) per kg liveweight. Lateral testicular diameter was measured with electronic calipers (Tru-Test NZ Ltd). The bucks were then electroejaculated by using a rectal probe $(2.5 \mathrm{~cm}$ in diameter and $25 \mathrm{~cm}$ in length, with 2 lateral electrodes) powered by a $12 \mathrm{~V}$ dry cell battery. The probe was liberally coated with lubricating gel and inserted about $15 \mathrm{~cm}$ into the rectum. A single ejaculate was collected into pre-warmed glass semen vials $(25 \mathrm{ml}$ capacity) after 2 or 3 electric stimulations ( $\sim 5 \mathrm{sec}$ duration each) about $5 \mathrm{sec}$ apart. The ejaculate was immediately transferred to a water bath at $37^{\circ} \mathrm{C}$.

Semen appraisal. Ejaculate volume was measured to the nearest $0.05 \mathrm{ml}$ after being drawn into a pre-warmed pipette attached to a graduated syringe. Sperm concentration was measured from diluted raw semen $(0 \cdot 10 \mathrm{ml}$ semen with $20 \mathrm{ml} 2 \%(\mathrm{w} / \mathrm{v})$ saline solution; 1 in 201 dilution) at $580 \mathrm{~nm}$ wavelength in a spectrophotometer (Spectronic 20, Bausch \& Lomb) that was frequently calibrated against known concentrations of bull and ram semen (NZ Dairy Board, Newstead, Hamilton, NZ). The percentage of motile spermatozoa was estimated by observation of thin films of diluted (ejaculates with high sperm concentration) or undiluted (low concentration) semen prepared between a microscope slide and coverslip, and viewed under phase-contrast optics $(\times 400)$. The presence of morphologically abnormal spermatozoa (i.e. head and tail separation) and cellular debris was noted.

Testosterone assay. Serum testosterone concentrations were assayed by a method similar to that described by Peterson et al. (1978) but omitting the chromatographic step used to separate androgens. The antiserum used in the assay was raised in a goat against testosterone-3-O-carboxymethyloxime-BSA conjugate and was used at a final dilution of 1:4500. There was no appreciable cross-reactivity (i.e. $<0 \cdot 1 \%$ ) with any other steroids which were tested in the assay, including a wide range of androgens, oestrogens and progestagens. All samples from an individual were included within a single assay. Low and high testosterone control samples (sera from entire bucks) were included at least once in each assay. The inter-assay coefficients of variation were $8.4 \%$ for the low control $(n=15$, mean $=0.65 \mathrm{ng} / \mathrm{ml})$ and $14 \cdot 2 \%$ for the high control $(n=21$, mean $=1.96 \mathrm{ng} / \mathrm{ml})$. The intra-assay coefficient of variation, calculated from 50 duplicates randomly selected across all assays, was $4.2 \%$. The mean ( \pm s.d.) recovery of testosterone added to charcoal-stripped serum from a castrated buck (10 determinations) was $84 \cdot 2 \pm 4 \cdot 1 \%$ at $200 \mathrm{pg} / \mathrm{ml}$ and $76.0 \pm 7.8 \%$ at $2000 \mathrm{pg} / \mathrm{ml}$. Serum values were not corrected for recovery rate. Extraction efficiency of radioactive testosterone in fallow doe serum was $87 \cdot 3 \pm 2 \cdot 4 \%$. The sensitivity of the standard curve was $5 \mathrm{pg} /$ tube $(50 \mathrm{pg} / \mathrm{ml} \mathrm{serum})$.

Melatonin pellets. Crystalline melatonin (Sigma Chemical Company, St Louis, MO, U.S.A.) was dissolved in ethanol and the solution sprayed onto a pelleted lucerne-based concentrate (Deer nuts; Northern Roller Mills Feeds Ltd, Auckland, NZ) at 2 rates; $2.5 \mathrm{mg}$ melatonin $/ 100 \mathrm{~g}$ of feed ('low') and $10.0 \mathrm{mg}$ melatonin $/ 100 \mathrm{~g}$ ('high'). The pellets containing absorbed melatonin were divided into daily group allowances $(1.4 \mathrm{~kg}=200 \mathrm{~g}$ per buck) and stored at $-10^{\circ} \mathrm{C}$ until required.

Melatonin treatment of entire bucks. At 15:30 h daily from 22 November to 14 January 1984, pellets were offered to the bucks at a rate of $200 \mathrm{~g}$ per buck. Group A bucks received 'low' concentration melatonin pellets ( $5 \mathrm{mg}$ melatonin per buck), Group B bucks received 'high' concentration melatonin pellets ( $20 \mathrm{mg}$ melatonin per buck) and Group C continued to receive untreated pellets during a 45-day treatment period between 1 December 1983 and 14 January 1984. The pellets were provided in long $(5 \mathrm{~m})$ wooden troughs.

The timing of daily melatonin administration was intended to simulate the physiological effects of the natural photoperiod during summer which would normally occur during the rut in autumn (i.e. $\sim 12 \mathrm{~h}$ ).

Statistical analysis. Univariate analysis of variance, in which variates significantly correlated with liveweight (i.e. neck girth) were simultaneously adjusted by covariance to a pre-trial (October 1983) liveweight and current liveweight, was performed to examine seasonal changes in the monitored parameters and differences between control, melatonin-treated and castrated bucks on each sampling date. When $F$ values indicated significant differences, individual means were compared by Student's $t$ test. Serum testosterone data were routinely subjected to logarithmic transformation for statistical analysis. 


\section{Results}

Seasonal profiles of entire and castrated bucks

As shown in Fig. 1, throughout the trial the entire bucks were significantly heavier than the castrated bucks $(P<0.05)$; in October $1983(22$ months of age) they were $\sim 14 \%$ heavier than castrated bucks and this margin increased to $\sim 18 \%$ by November 1984 (35 months of age). Both groups exhibited liveweight gains over the late spring and summer period (October-March 1983/84 and October-November 1984). Over the 2-month period spanning the rut (April and May 1984) the entire bucks showed a marked decline in mean liveweight, with the lowest mean values which occurred in early May $(54.2 \mathrm{~kg})$ being significantly different $(P<0.05)$ from the peak mean value recorded previously in late February $(59.8 \mathrm{~kg})$. The castrated bucks showed no significant liveweight changes over the same period $(P>0 \cdot 1)$.

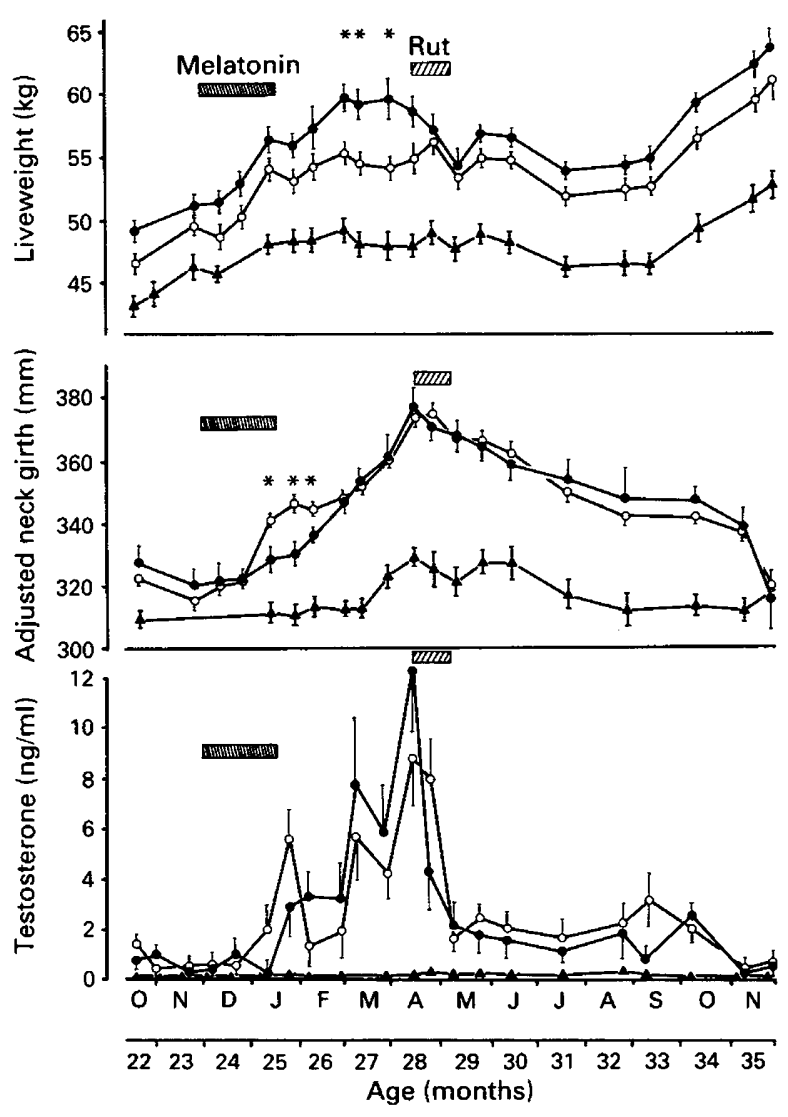

Fig. 1. Seasonal profiles of mean ( \pm s.e.m.) liveweight, adjusted neck girth and serum testosterone concentrations recorded from 7 control entire $(\Theta), 14$ melatonin-treated entire $(O)$ and 11 prepubertally castrated $(\Delta)$ fallow bucks from 22 to 35 months of age. The period of the rut and melatonin treatment are indicated by the shaded bars. Asterisks indicate significant $(P<0.05)$ differences between the means of control-entire and melatonin-treated entire bucks. 
Neck girth measurements were significantly correlated with individual liveweights on each sampling date $(P<0.05)$. After covariance adjustment there were significant $(P<0.05)$ seasonal changes in mean neck girth of entire bucks over the study period. Mean adjusted and non-adjusted neck girth increased steadily from mid-December 1983 (mid-summer) until mid-April 1984 (autumn), immediately before the onset of the rut, and thereafter steadily declined until August 1984 (late winter). For the entire bucks, mean non-adjusted neck girth remained constant until the end of the trial period in November 1984 whilst mean adjusted neck girth declined further. Their mean non-adjusted neck girth was about $6 \%$ greater in October 1984 than in the previous October, but this was not significant after adjustment for liveweight $(P>0 \cdot 1)$. Castrated bucks also exhibited significant $(P<0.05)$, but less pronounced, changes in mean adjusted neck girth, with definite increases occurring immediately before the rutting period. The mean adjusted neck girths of entire and castrated bucks were significantly different $(P<0.05)$ at all times except the final sampling date ( 28 November) when they were virtually identical.

Mean serum testosterone concentrations of entire bucks showed a progressive but erratic increase from mid-summer until immediately before the onset of the rut. Mean values rose from $<1.0 \mathrm{ng} / \mathrm{ml}$ in October and November 1983 to reach a peak of $>12.0 \mathrm{ng} / \mathrm{ml}$ in mid-April. During the rut, mean serum testosterone concentrations declined rapidly to reach relatively constant values between 1.0 and $2.0 \mathrm{ng} / \mathrm{ml}$ over the winter and early spring periods (May-October 1984), and gradually declined to basal values of $<1.0 \mathrm{ng} / \mathrm{ml}$ by November 1984 . Serum testosterone concentrations of castrated bucks remained very low $(<0.3 \mathrm{ng} / \mathrm{ml})$ throughout the study period.

Seasonal profiles of mean testicular diameter, ejaculate volume, sperm density and percentage of motile spermatozoa for the 5 fertile entire bucks are presented in Fig. 2. Testicular diameter measurements were poorly correlated with individual liveweights on each sampling date $(P>0 \cdot 1)$, and so covariance adjustments were not performed. The seasonal profile of testicular diameter for these bucks was similar to that of neck girth, with progressive increases over summer and early autumn. Peak mean diameter for these bucks was recorded immediately before the rut period and was followed by a gradual decline in testicular size through winter and early summer, until the testes had returned to the size observed at the start of monitoring.

There was no consistent $(P>0 \cdot 1)$ seasonal variation in mean ejaculate volume (range $0.12-0.21 \mathrm{ml}$ ). However, there was considerable seasonal variation in sperm concentration and percentage of motile spermatozoa. Very low concentrations of spermatozoa were detected in November (1983 and 1984) and late January (1984) ejaculates, and all the spermatozoa present had heads separated from tails. Ejaculates collected in late March (pre-rut), mid-June (post-rut) and September (early spring) contained successively increasing numbers of motile spermatozoa. Few, if any, abnormal spermatozoa (e.g. head and tail separation) were detected in these ejaculates.

\section{Effects of melatonin treatment in summer}

All data from the 2 melatonin treatment groups (A \& B) were pooled as there were no significant differences $(P>0 \cdot 1)$ for any of the parameters measured on any sampling date. Seasonal profiles of means of the measurements taken are presented in Figs 1 and 2.

The initial liveweight bias between the control and melatonin-treated bucks (mean \pm s.d. $=$ $51 \cdot 2 \pm 2 \cdot 2 \mathrm{~kg}$ and $49 \cdot 4 \pm 2 \cdot 4 \mathrm{~kg}$ respectively; $P>0 \cdot 1$ ) persisted throughout the trial period (Fig. 1). However, only during the period from 27 February to 26 March inclusive, were mean liveweights of the control bucks significantly heavier than those of melatonin-treated bucks $(P<0.05)$.

Mean adjusted neck girths of the melatonin-treated bucks were significantly larger $(P<0.05)$ than those of the control bucks only on the 3 sampling dates between 12 January and 7 February inclusive (Fig. 1). This was the 3-week period which spanned the cessation of melatonin treatment.

At no time during the monitoring period were there significant differences $(P>0 \cdot 1)$ between mean serum testosterone concentrations of the control and melatonin-treated bucks. However, 


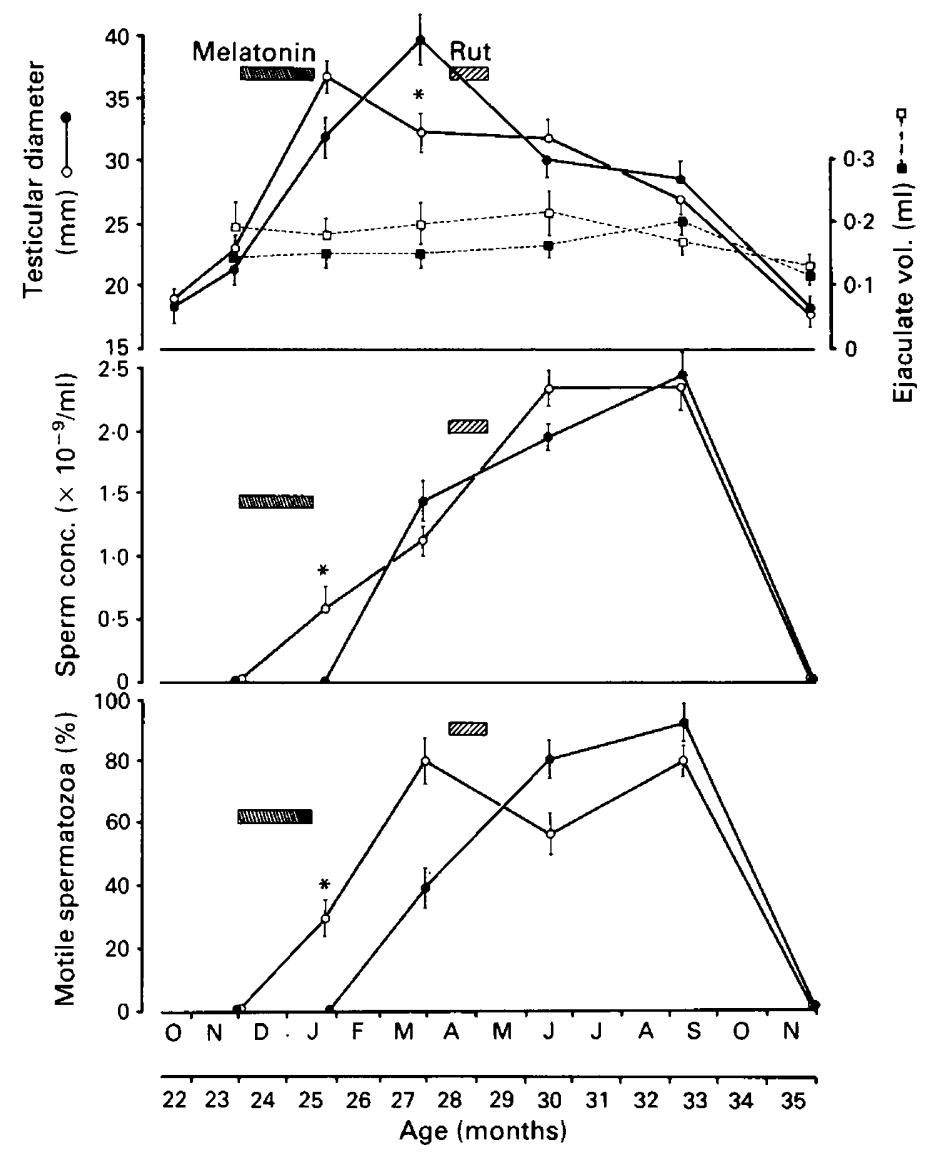

Fig. 2. Seasonal profiles of mean ( \pm s.e.m.) testicular diameter, ejaculate volume, sperm concentration and percentage of motile spermatozoa in ejaculates, recorded from 5 control $(\bullet, \mathbf{0})$ and 14 melatonin-treated $(O, \square)$ entire fallow bucks from 22 to 35 months of age. The melatonin treatment period and the natural rut period are indicated by the shaded bars. Asterisks indicate significant $(P<0.05)$ differences between the means of control and treated bucks.

mean testicular diameter of melatonin-treated bucks was highest on 25 January, the sampling date closest to the cessation of melatonin treatment. In contrast, mean testicular diameter of the control bucks was highest 2 months later (Fig. 2). The difference in mean diameter between the 2 groups of bucks was significant $(P<0.05)$ only on 26 March.

While mean ejaculate volumes were not significantly different $(P>0 \cdot 1)$ between control and melatonin-treated bucks at any sampling date (Fig. 2), ejaculates collected from melatonintreated bucks on 25 January 1984 (immediately after treatment) had mean values of $\sim 500 \times 10^{6}$ spermatozoa $/ \mathrm{ml}$ ejaculate and $\sim 30 \%$ motile spermatozoa. This was in marked contrast to ejaculates, devoid of motile spermatozoa, collected from control bucks on the same day. Peak mean values of the various parameters were of similar magnitude for melatonin-treated and control bucks but they tended to occur on different sampling dates (Fig. 2). For instance, peak numbers of spermatozoa were recorded from ejaculates of melatonin-treated bucks on 13 June, but the corresponding peak for control bucks was recorded on 5 September. The elevation in mean percentage of motile spermatozoa occurred earlier in semen from treated bucks than in semen from the control bucks. 


\section{Discussion}

A distinct annual pattern of reproductive seasonality in entire fallow bucks is evident from the characteristics measured in this study. The annual cycle of testicular enlargement and regression is in general agreement with that recorded from studies of killed bucks in Britain (Chapman \& Chapman, 1970, 1975; Chaplin \& White, 1972) and New Zealand (Baker, 1973).

Seasonal liveweight changes of the 7 entire control bucks followed expected trends in relation to the rut, the period of intense mating activity in autumn. It has been stated, but not empirically demonstrated, that the rutting period of fallow bucks is associated with a rapid loss in liveweight (Chapman \& Chapman, 1975). While liveweight loss occurred in the present study, the degree of loss $(9.4 \%)$ in these bucks, run as a bachelor herd, was considerably less than that of 3 older bucks used as sires in 1983 and 1984 ( 25\%; Asher, 1986).

The increase in neck girth approaching the rut in fallow bucks is mainly due to a 2.6 fold increase in splenius muscle mass between January and April in New Zealand (Field et al., 1985). While testosterone-related splenius muscle development is common in adult male mammals, such as sheep (Jury et al., 1977), only in male deer is there a post-rut regression in mass (Lincoln, 1971). Therefore the splenius muscle could possibly be regarded as a target organ for androgens and is very sensitive to seasonally changing levels of androgens in male deer. Measurements of changes in muscle mass (e.g. neck girth) may provide a useful indicator of seasonal androgen secretion in these animals. Seasonal changes in mean neck girth appeared to be closely related to the seasonal changes in mean serum testosterone concentrations in entire fallow bucks. This relationship held true after neck girth measurements were adjusted for liveweight.

Annual testosterone secretion profiles of entire male red deer (Bartecki \& Jaczewski, 1983; Barrell et al., 1985), wapiti (Haigh et al., 1984), white-tailed deer (McMillin et al., 1974; Mirarchi et al., 1978) and roe deer (Schams \& Barth, 1982; Sempere \& Lacroix, 1982) all exhibit marked seasonality, with major elevations of blood testosterone concentrations starting 2-3 months before the onset of the rutting season, reaching peak values before the rut and declining during, or shortly after, the rutting season. The entire fallow bucks in the present study did not differ markedly from other species of deer of northern temperate origin. However, it was noticeable that mean serum testosterone levels in the entire control bucks declined during the rutting period (Fig. 1). This was also observed with older, sire bucks (Asher, 1986). Clearly rutting activity, and hence liveweight loss, did not reflect peak testosterone secretion by the testes, as the 2 former events were not in synchrony with the peak serum testosterone concentrations.

Peak pre-rut concentrations of serum testosterone in fallow bucks appear to be considerably higher than required for the maintenance of normal sexual activity during the mating period which closely follows. The physiological relevance of the magnitude of the pre-rut serum testosterone peaks is open to speculation. There was a close relationship between mean testicular diameter, serum testosterone concentrations and neck girth, with all three of these measures attaining maximal mean values just before the onset of the rut. This may indicate that high levels of testicular testosterone secretion are required for the rapid final development of secondary sexual characteristics before the start of the rut. The prepuce of adult fallow bucks also undergoes marked histological changes immediately before the onset of the rut. These include gross hyperkeratosis, hypertrophy of the epidermis, enlargement of the sebaceous and sweat glands and the deposition of lipids (Kennaugh et al., 1977). Similarly, the ampullae, prostate gland and seminal vesicles of mature bucks attain maximal dimensions just before the onset of the rut (Chapman \& Chapman, 1979). The secondary sexual characteristics probably represent target actions of androgens and full development just before the rut may require extremely high concentrations of testosterone in the blood.

Sperm production of control bucks, as reflected by mean sperm concentration and percentage motility, did not peak until about 4 months after the rut (Fig. 2). As ejaculates were collected at 2-monthly intervals, it is possible that maximal sperm production actually occurred slightly earlier 
than indicated by the present data, but it was still well after the rut period. Several explanations are possible. Firstly, the high secretion rate of testosterone may be inhibitory to maximal spermatogenesis during the pre-rut period. In support of this is the finding that exogenous testosterone (i.e. high doses) exerted a dose-dependent inhibition of spermatogenesis in the ram (Courot et al., 1979; Schanbacher, 1980) possibly due to a reduction in the number of spermatogonia entering meiosis (Courot et al., 1979). Therefore submaximal serum testosterone values measured in fallow bucks during and after the rut may be more suitable for maximal sperm production than the peak concentrations which occurred before the rut. Secondly, spermatogenesis is perhaps stimulated by high pre-rut levels of serum testosterone, but there is an interval of between 2 and 4 months between the onset of spermatogenesis and the occurrence of the mature spermatozoa in the semen. As with fallow deer in this study, Byers et al. (1983) observed that the highest mean plasma testosterone concentrations in male horses were not associated temporally with optimal semen quality. They attributed the 60-day hiatus between peak androgen levels and peak semen quality to the length of the spermatogenic cycle plus the period of transit of spermatozoa through the epididymis. Chapman \& Chapman's (1975) observation that the testes of mature fallow bucks displayed the highest levels of spermatogenesis during the immediate pre-rut and rut periods supports this hypothesis. Thirdly, electroejaculation studies may not necessarily provide an accurate assessment of fertility changes; responses to the technique are known to be inconsistent. While natural ejaculation would be the preferred method of semen collection, it has not yet proved to be possible with fallow deer.

Prepubertal castration of fallow bucks had marked effects on the annual cycles of liveweight change and neck girth, presumably due to the apparent suppression of the serum testosterone cycle. Nevertheless, castrated bucks still exhibited seasonal patterns of liveweight change and neck development and these were similar to those of the entire bucks, although less pronounced. Whether this was in response to possible extra-gonadal secretion of testosterone which produced physiologically significant serum testosterone concentrations that were below the sensitivity of the assay used in this study, or merely reflects circannual rhythms of other hormones that have influences on these characteristics cannot be ascertained from the present study.

Melatonin treatment produced some changes in the seasonal attainment of fertility in entire fallow bucks, indicating that changing daily photoperiod and the pineal gland have a role in the timing of the annual reproductive cycle of this species. While control bucks exhibited marked changes in mean liveweight during and after the melatonin treatment period, the melatonin-treated bucks maintained a relatively stable mean liveweight until the middle of the rut period. In rams, long-term (3-5 months) melatonin treatment eventually inhibited liveweight gains or resulted in liveweight losses in adults and juveniles (Lincoln \& Ebling, 1985). Lincoln \& Ebling (1985) suggested that this condition may be due to reduced prolactin secretion which occurs as a result of melatonin treatment, as has been observed in sheep (Kennaway et al., 1981; Symons et al., 1983) and red deer (Webster \& Barrell, 1985). Serum prolactin concentrations were not measured in the present study on fallow bucks. The apparent differences in liveweight changes between the control and melatonin-treated fallow bucks occurred at least 45 days after the cessation of melatonin treatment, somewhat later than the differences in other measures. However, this does not eliminate the possibility of delayed effects of melatonin treatment on liveweight cycles.

The mean neck girth profiles clearly showed that this muscle development responded to melatonin treatment, suggesting that this secondary sexual characteristic was sensitive to changing daily photoperiods. This response to only 45 days of melatonin treatment was transient and neck muscle development appeared subsequently to be halted for a short period (2-3 weeks) after the cessation of melatonin treatment. Thereafter, neck muscle development in the melatonin-treated bucks up to and beyond the rut period was not different from that of the control bucks. Similarly, Lincoln et al. (1984) reported that neck girths of red deer stags apparently increased during summer in response to $\sim 80$ days of treatment with melatonin, although measurements were taken only once during the study. Lincoln et al. (1984), Bubenik (1983) and Adam \& Atkinson (1984) relied on 
changes in antler mineralization to indicate responses to melatonin treatment. Although Lincoln et al. (1984) demonstrated an increase in mean plasma testosterone concentrations which was associated with advanced antler mineralization in melatonin-treated red deer stags, the present study on fallow deer did not record significant differences in mean peripheral blood concentrations of testosterone between the melatonin-treated and control bucks at any time during the 13-month study period. Lincoln et al. (1984) assessed testicular responsiveness to an LH challenge, but the present study relied upon testosterone concentrations of blood samples from unchallenged fallow bucks. Nevertheless, the profiles of mean serum testosterone concentrations depicted in Fig. 1 do not reflect the pulsatile secretory pattern of testosterone because of the wide sampling interval used in this study and therefore may not accurately indicate the secretory activity of the testes.

Some differences between melatonin-treated and control bucks were apparent for mean testicular and sperm measures. The treated bucks exhibited an earlier attainment of peak mean testicular diameter. While this has been well documented for rams treated with melatonin implants during long daily photoperiods (Lincoln \& Ebling, 1985) it was not apparent in melatonin-treated red deer stags for which testicular diameter measurements were recorded only once during the trial (Lincoln et al., 1984). No previous studies on deer or other domestic ruminants have investigated the effects of melatonin treatment on sperm production and viability. The onset of reproductive competence, in terms of sperm concentration, numbers of spermatozoa per ejaculate and proportion of motile spermatozoa, was advanced in the melatonin-treated bucks. The appearance of viable spermatozoa in the ejaculates of melatonin-treated bucks in mid-January, immediately after the melatonin treatment regimen, was in stark contrast to the complete absence of viable spermatozoa in the ejaculates collected from control bucks on the same date, even though mean testicular diameter was increasing for both groups of bucks. This is of particular relevance to the advancement of the breeding season in fallow deer.

We thank Dr J. L. Adam, Dr K. L. Macmillan and Dr A. J. Peterson for advice during this study; R. James for semen appraisal; M. Langridge, K. Hargreaves, H. Humble, B. Mather, C. Chitty, and other staff at the Ruakura Deer Unit, for technical assistance; and D. Duganzich for statistical advice.

\section{References}

Adam, C.L. \& Atkinson, T. (1984) Effect of feeding melatonin to red deer (Cervus elaphus) on the onset of the breeding season. J. Reprod. Fert. 72, 463-466.

Asher, G.W. (1985) Meat production from fallow deer. In Biology of Deer Production, pp. 299-301. Eds P. F. Fennessy \& K. R. Drew. Royal Society of New Zealand, Bulletin No. 22, Wellington.

Asher, G.W. (1986) Studies on the reproduction of farmed fallow deer, Dama dama. Ph.D. thesis, Lincoln College, University of Canterbury, New Zealand.

Baker, K. (1973) Reproduction biology of fallow deer (Dama dama) in the Blue Mountains of New Zealand. M.Sc. thesis, University of Otago.

Barrell, G.K., Muir, P.D. \& Sykes, A.R. (1985) Seasonal profiles of plasma testosterone, prolactin and growth hormone in red deer stags. In Biology of Deer Produc tion, pp. 185-190. Eds P. F. Fennessy \& K. R. Drew. Royal Society of New Zealand, Bulletin No. 22, Wellington.

Bartecki, R. \& Jaczewski, Z. (1983) Seasonal variation in the plasma androgens concentration of red deer. Acta theriol. 28, 333-336.
Bubenik, G.A. (1983) Shift of seasonal cycle in whitetailed deer by oral administration of melatonin. $J$. exp. Zool. 225, 155-156.

Byers, S.W., Dowsett, K.F. \& Glover, T.D. (1983) Seasonal and circadian changes of testosterone levels in the peripheral blood plasma of stallions and their relation to semen quality. $J$. Endocr. 99, 141-150.

Chaplin, R.E. \& White, R.W. (1972) The influence of age and season on the activity of the testes and epididymides of the fallow deer, Dama dama. J. Reprod. Fert. 30, 361-369.

Chapman, D.I. \& Chapman, N.G. (1970) Preliminary observations on the reproductive cycle of male fallow deer (Dama dama L.). J. Reprod. Fert. 21, 1-8.

Chapman, D.I. \& Chapman, N. (1975) Fallow Deer: their History, Distribution and Biology. Terence Dalton Ltd, Laveham.

Chapman, N.G. \& Chapman, D.I. (1979) Seasonal changes in the male accessory gland of reproduction in adult fallow deer (Dama dama). J. Zool., Lond. 189, 259-273.

Courot, M., Hochereau-de Reviers, M.T., Monet-Kuntz, 
C., Locatelli, A., Pisselet, C., Blanc, M.R. \& Dacheux, J.L. (1979) Endocrinology of spermatogenesis of the hypophysectomized ram. J. Reprod. Fert., Suppl. 26, $165-173$.

Eaton, D. (1980) Factors affecting the behaviour and reproductive cycle of fallow deer. Ratel 7, 5-8.

Field, R.A., Young, O.A., Asher, G.W. \& Foote, D.M. (1985) Characteristics of male fallow deer muscle at a time of sex-related muscle growth. Growth 49, $190-201$.

Goss, R.J. (1983) Deer Antlers; Regeneration, Function and Evolution. Academic Press, New York.

Haigh, J.C., Cates, W.F., Glover, G.J. \& Rawlings, N.C. (1984) Relationships between seasonal changes in serum testosterone concentrations, scrotal circumference and sperm morphology of male Wapiti (Cervus elaphus). J. Reprod. Fert. 70, 413-418.

Jaczewski, Z. (1954) The effect of changes in length of daylight on the growth of antlers in deer (Cervus elaphus L.). Folia Biol., Praha 2, 133-143.

Jury, K.E., Fourie, P.D. \& Kirton, A.H. (1977) Growth and development of sheep IV. Growth of the musculature. N.Z. Jl Agric. Res. 20, 115-121.

Kennaugh, J.H., Chapman, D.I. \& Chapman, N.G. (1977) Seasonal changes in the prepuce of adult fallow deer (Dama dama) and its probable function as a scent organ. J. Zool., Lond. 183, 301-310.

Kennaway, D.J. \& Seamark, R.F. (1980) Circulating levels of melatonin following its oral administration or subcutaneous injection in sheep and goats. Aust. $J$. biol. Sci. 33, 349-353.

Kennaway, D.J., Gilmore, T.A. \& Seamark, R.F. (1981) The effect of melatonin feeding on serum prolactin, gonadotrophins and the onset of estrous activity in seasonally anestrous ewes. Biol. Reprod. 24, Suppl. 1, 109, Abstr.

Lincoln, G.A. (1971) The seasonal reproductive changes in the red deer stag (Cervus elaphus). J. Zool., Lond. 163, $105-123$.

Lincoln, G.A. \& Almeida, O.F.X. (1981) Melatonin and the seasonal photoperiodic response in sheep. In Photoperiodism and Reproduction, pp. 231-251. Eds R. Ortavant, J. Pelletier \& J.-P. Ravault. INRA, France.

Lincoln, G.A. \& Ebling, F.J.P. (1985) Effect of constantrelease implants of melatonin on seasonal cycles in reproduction, prolactin secretion and moulting in rams. J. Reprod. Fert. 73, 241-253.

Lincoln, G.A., Fraser, H.M. \& Fletcher, T.J. (1984) Induction of early rutting in male red deer (Cervus elaphus) by melatonin and its dependence on LHRH. J. Reprod. Fert. 72, 339-343.
McMillin, J.M., Seal, U.S., Keenlyne, K.D., Erickson, A.W. \& Jones, J.E. (1974) Annual testosterone rhythm in the adult white-tailed deer (Odocoileus virginianus borealis). Endocrinology 94, $1034-1040$.

Mirarchi, R.E., Howland, B.E., Scanlon, P.F., Kirkpatrick, R.L. \& Sanford, L.M. (1978) Seasonal variation in plasma $\mathbf{L H}, \mathrm{FSH}$, prolactin, and testosterone concentrations in adult male white-tailed deer. Can. J. Zool. 56, 121-127.

Nett, T.M. \& Niswender, G.D. (1982) Influence of exogenous melatonin on seasonality of reproduction in sheep. Theriogenology 17, 645653 .

Peterson, A.J., Fairclough, R.J. \& Smith, J.F. (1978) Radioimmunoassay of androstenedione and testosterone in cow plasma at the time of luteolysis and oestrus. J. Reprod. Fert. 52, 127-129.

Rollag, M.D., O'Callaghan, P.O. \& Niswender, G.D. (1978) Serum melatonin concentrations during different stages of the annual reproductive cycle in ewes. Biol. Reprod. 18, 279-285.

Schams, D. \& Barth, D. (1982) Annual profiles of reproductive hormones in peripheral plasma of the male roe deer (Capreolus capreolus). J. Reprod. Fert. 66, 463-468.

Schanbacher, B.D. (1980) Dose-dependent inhibition of spermatogenesis in mature rams with exogenous testosterone. Int. J. Androl. 3, 563-573.

Sempere, A.J. \& Lacroix, A. (1982) Temporal and seasonal relationships between $\mathrm{LH}$, testosterone and antlers in fawn and adult male roe deer (Capreolus capreolus L.): a longitudinal study from birth to four years of age. Acta endocr., Copenh. 99, 295-301.

Symons, A.M., Arendt, J. \& Laud, C.A. (1983) Melatonin feeding decreases prolactin levels in the ewe. $J$. Endocr. 99, 41-46.

Thibault, C., Courot, M., Martinet, L., Mauleon, P., du Mesnil du Buisson, F., Ortavant, R., Pelletier, J. \& Signoret, J.P. (1966) Regulation of breeding season and estrous cycle by light and external stimuli in some mammals. J. Anim. Sci. 25, Suppl. 119-142.

Webster, J.R. \& Barrell, G.K. (1985) Advancement of reproductive activity, seasonal reduction in prolactin secretion and seasonal pelage changes in pubertal red deer hinds (Cervus elaphus) subjected to artificially shortened daily photoperiod or daily melatonin treatments. $J$. Reprod. Fert. 73, 255-260. 